\title{
The subsidiary Gntll system for gluconate metabolism in Escherichia coli: Alternative induction of the gntV gene
}

\author{
Keyla M Gómez, Andrea Rodríguez, Yesseima Rodriguez, Alvaro H Ramírez and Tomás Istúriz \\ Laboratorio de Fisiología y Genética de Microorganismos. Departamento de Biología Celular, Centro de Biología Celular e Instituto de Biología Experimental, \\ Facultad de Ciencias, Universidad Central de Venezuela, Apartado 47557, Caracas 1041-A, Venezuela.
}

\begin{abstract}
Two systems are involved in the transport and phosphorylation of gluconate in Escherichia coli. GntI, the main system, consists of high and low-affinity gluconate transporters and a thermoresistant gluconokinase for its phosphorylation. The corresponding genes, gnt $\mathrm{T}$, gnt $\mathrm{U}$ and gnt $\mathrm{K}$ at $76.5 \mathrm{~min}$, are induced by gluconate. GntII, the subsidiary system, includes IdnT and GntV, which duplicate activities of transport and phosphorylation of gluconate, respectively. Gene $g n t \mathrm{~V}$ at $96.8 \mathrm{~min}$ is divergently transcribed from the idnDOTR operon involved in L-idonate metabolism. These genetic elements are induced by the substrate or 5-keto-D-gluconate. Because gnt $\mathrm{V}$ is also induced in cells grown in gluconate, it was of interest to investigate its expression in this condition. E. coli gntK, $i d n \mathrm{O}<>k a n$ mutants were constructed to study this question. These $i d n \mathrm{O}$ kan-cassete inserted mutants, unable to convert gluconate to 5-keto-D-gluconate, permitted examining gnt $\mathrm{V}$ expression in the absence of this inducer and demonstrating that it is not required when the cells grow in gluconate. The results suggest that E. coli gnt $\mathrm{V}$ gene is alternatively induced by 5-keto-D-gluconate or gluconate in cells cultivated either in idonate or gluconate. In this way, the control of $g n t \mathrm{~V}$ expression would seem to be involved in the efficient utilization of these substrates.
\end{abstract}

Key terms: E. coli, gluconate, GntII, gntV.

\section{INTRODUCTION}

The genetics and physiology of transport and phosphorylation of gluconate (Gnt) in Escherichia coli have turned out to be highly complex (Fig. 1). Previous work has described the genes involved, as well as their regulation. There are two systems encoded by operons distinctly regulated and located in different regions of the bacterial chromosome (Bächi and Kornberg, 1975, Istúriz et al., 1979). GntI, the main system, consists of high and low affinity gluconate transporters (GntT, $\mathrm{GntU}$ ) and a thermoresistant gluconate kinase (GntK, Fig.1A). The gnt $\mathrm{T}$ and the gntKU genes constitute two operons located in the bioH-asd region of the chromosome at 76.4 and $77.1 \mathrm{~min}$, respectively, on the E. coli map (Fig.1B). These operons, as well as that of the Entner Doudoroff pathway (EDP, edd-eda), are induced by gluconate and negatively controlled by the gntR gene product $(77.1 \mathrm{~min})$ in a regulatory network known as the gntR regulon (Zwaig et al., 1973, Tong, et al., 1996, Izu et al., 1997, Peekhaus and Conway, 1998).

GntII, the subsidiary system, contains another high affinity gluconate transporter ( $\mathrm{IdnT}$ ) and also a thermosensitive gluconate kinase (GntV, Fig.1A). It was revealed by the gluconate negative phenotype of BBI, an E. coli mutant carrying two lesions linked to $f d p$ and malA markers, affecting a subsidiary gluconate transporter and the regulatory gnt $\mathrm{R}$ gene respectively (Bächi and Kornberg, 1975). Later, it was confirmed by the selection in mineral medium with gluconate of spontaneous fermenting pseudorevertants of $E$. coli HfrG6 $4 \mathrm{MD} 2$, a bioH-gntTKUR-asd deleted mutant that cannot grow in gluconate. One representative pseudorevertant, mutant $\mathrm{C} 177(\Delta g n t \mathrm{R})$, expressed the dehydratase (edd, $41 \mathrm{~min})$ in mineral medium with glucose and formed when grown in media with gluconate, both a high-affinity transporter for this substrate and the thermosensitive gluconokinase. The lesion responsible for this gluconate positive phenotype designated as gnt177 was located at $96 \mathrm{~min}$ on the map, $76 \%$ linked to $p y r \mathrm{~B}$ (Istúriz et al., 1979).

Much has been learned about the GntII system over the present and past two decades. Gene $g n t \mathrm{~V}$, located at $96.8 \mathrm{~min}$ (Istúriz et al., 1986, Burland et al., 1995), is monocistronic and divergently transcribed from the idnDOTR operon (Fig.1B), which encodes enzymes that metabolizes L-idonic acid (Idn) to D-gluconate (Bausch et al., 1998). Enzyme IdnD, an L-idonate 5-dehydrogenase, converts incorporated idonate to 5-ketoD-gluconate $(5 \mathrm{KG})$, which in turn is transformed to gluconate by IdnO, a 5-keto-D-gluconate 5-reductase. Gluconate is then phosphorylated to 6-phosphogluconate by GntV (IdnK), whose gene is coordinately induced with the $i d n$ DOTR operon. IdnT was found to function as a permease for transport of both idonate and gluconate, indicating that the GntII system contains the enzymes of a pathway for idonate catabolism where gluconate is an intermediate (Fig. 1A). IdnR was identified as a positive regulator of the idnR regulon with $5 \mathrm{KG}$ as the inducer (Bausch et al., 1998). A negative regulatory effect of IdnR on the gntT, gntKU and edd-eda operons (not shown in Fig.1) is indicative of a cross-regulation between the gntR and idnR regulons (Tsunedomi et al., 2003a, Ramírez et al., 2007).

The fact that $g n t \mathrm{~V}$ is also induced in wild type cells grown in gluconate led us to wonder whether this expression is also under the positive control of the $5 \mathrm{KG}-\mathrm{IdnR}$ complex. Previous reports do not favor this possibility, so the present work was undertaken to resolve the question. Although cells grown in gluconate display a poor induction of the idnDOTR operon, there is strong induction of $\mathrm{GntK}$ and $\mathrm{GntV}$ expression (Istúriz et al., 1986, Bausch et al., 2004). Moreover, in gluconate-limited mineral medium continuous culture, the total gluconate 
kinase activity, consisting of GntV at very low dilution rates (D), is gradually repressed as the induction of GntK increases as a consequence of the progressive increase of $\mathrm{D}$ and corresponding increment in the concentration of limiting substrate. These findings indicated that $g n t \mathrm{~V}$ induction, contrary to that of gnt $\mathrm{K}$, occurs mainly at low gluconate concentrations (Coello and Istúriz, 1992).

The possibility that gnt $\mathrm{V}$ expression occurs independently of the IdnR-5KG complex is also suggested by the complexity of the intergenic regulatory region between gnt $\mathrm{V}$ and $i d n \mathrm{D}$. This region includes promoter-operator sequences for the $g n t \mathrm{~V}$ gene and the $i d n D O T R$ operon, each with a binding element for GntR or IdnR. These regulators have $42 \%$ similarity between their entire primary sequences and $70 \%$ identity between their DNA-binding motifs. In addition, there are two binding sites for cAMP-CRP complex and another for GntR or IdnR (Izu et al., 1997, Tsunedomi et al., 2003b).

Here we demonstrate that the induction of $g n t \mathrm{~V}$ in $E$. coli grown in gluconate occurs in the absence of $5 \mathrm{KG}$ and is not coordinated with that of the $i d n$ DOTR operon; furthermore, in this condition gluconate is suggested as the inducer. The study involved the construction and analysis of two E. coli $g n t \mathrm{~K}, i d n \mathrm{O}<>k a n$ sets of mutants, differentiated by the presence of the mutation gnt177 in one of them. In the presence of this mutation the E. coli idnR regulon is induced by 5 KG formed from gluconate by IdnO activity (Ramírez 2004, Ramirez et al., 2007). The fact that gnt $\mathrm{K}, i d n \mathrm{O}<>k a n$ mutants grow in gluconate despite being disabled from converting it to the inducer $5 \mathrm{KG}$, revealed that in this case $\mathrm{g} n t \mathrm{~V}$ expression is independent of that of the $i d n D O T R$ operon and presumably is induced by gluconate. This alternative induction displayed by $g n t \mathrm{~V}$ seems to be important for an efficient utilization of the involved substrates. The results permit a better understanding of the cross-regulation between GntI and GntII systems.

\section{MATERIALS AND METHODS}

Bacterial strains

The Escherichia coli strains used in this study are listed in Table I. The genetic markers were previously reported (Berlyn et al., 1996).

\section{Media}

E. coli strains were grown in Luria-Bertani broth (LB) or mineral medium [MM (Tanaka et al., 1967)] or on LB plates, MM plates or gluconate bromthymol blue indicator plates

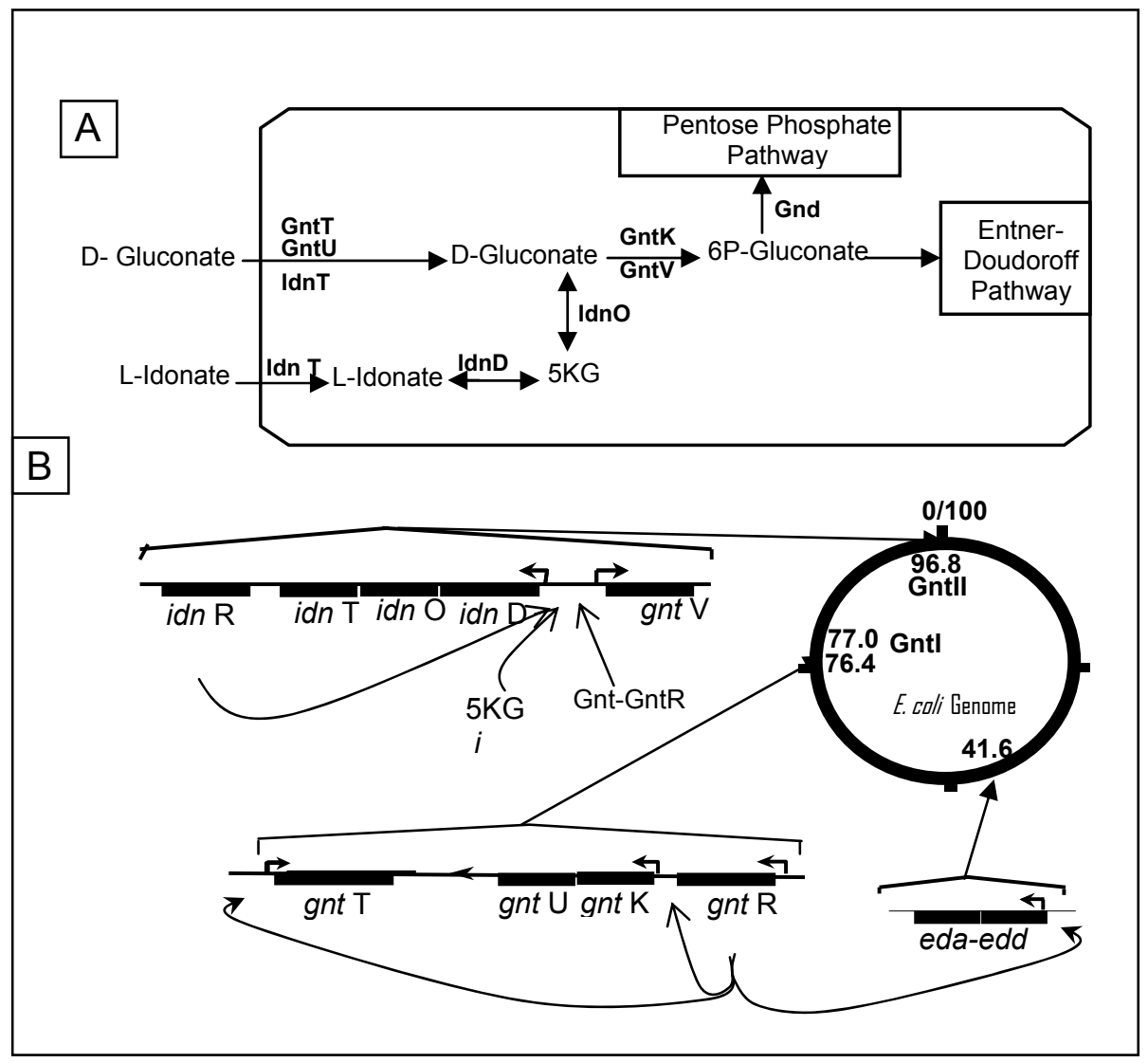

Fig. 1. Enzymes and respective genes of L-Idonate (Idn) and Gluconate (Gnt) catabolisms. Abreviations: 5KG, 5-keto-D-gluconate; GntT and GntU, Gntl permeases; GntK and GntV, Gntl and Gntll gluconate kinases respectively; IdnT idonate and gluconate permeases; IdnD, idonate dehydrogenase; IdnO, 5kG reductase; IdnR, idnR regulon regulator; GntR, gntR regulon regulator; Edd, Entner-Doudoroff dehydratase; Eda, Entner-Doudoroff aldolase. 
[GBTB (Istúriz, et al., 1986)]. MM was supplemented with carbon source as indicated at $2 \mathrm{~g} \mathrm{l}^{-1}, 5 \mu \mathrm{g} \mathrm{ml}^{-1}$ of thiamine hydrochloride, and $20 \mu \mathrm{g} \mathrm{ml}^{-1}$ of L-amino acids as required. If necessary, MM and rich media were supplemented with 500 and $40 \mu \mathrm{g} \mathrm{ml}^{-1}$ DL-a-e-diaminopimelic acid (DAPA) respectively. When required tetracycline (Tet) was used at $15 \mu \mathrm{g} \mathrm{ml}{ }^{-1}$, kanamycin (Kan) at $30 \mathrm{mg} \mathrm{ml}^{-1}$, and $5 \mathrm{KG}$ at $0.4 \%$.

\section{Growth conditions}

Cells were routinely grown aerobically at $37^{\circ} \mathrm{C}$, in volumes of $10 \mathrm{ml}$ for growth curves and $20 \mathrm{ml}$ for enzyme assays in $125 \mathrm{ml}$ flasks fitted with side arms, on a gyratory water bath (model G76, New Brunswick) at about 200 cycles min $^{-1}$. In each case, the growth was monitored by reading the optical density in a Klett colorimeter with a $\mathrm{N}^{\circ} 42$ filter.

Preparation of crude extracts

Cells were harvested by centrifugation, resuspended in $50 \mathrm{mM}$ Tris- $\mathrm{HCl} 10 \mathrm{mM} \mathrm{MgCl}$ ( $\mathrm{pH}$ 7.6) and disrupted with a Braun Sonic 2000 (12T probe, 45 wattage level) by three 20s sonication pulses (3 pulses) separated by 30 s cooling periods. Cell debris was, in each case, removed by centrifugation at 27000xg for 15 min.
Enzyme assays

Gluconokinase activity and its heat inactivation were assayed as previously described (Fraenkel and Horecker, 1964, Istúriz et al., 1986). Activities are reported as $\mathrm{nmol} \mathrm{min}^{-1}$ (mg protein) $)^{-1}$.

Phages and generalized transductions

The preparation of P1 lysates and generalized transductions were performed as reported (Miller, 1992) using a P1 phage stock kept in the laboratory.

DNA manipulations and transformations

Conventional and standard recombinant DNA techniques were employed (Sambrook et al., 1989).

Construction of mutants

To construct the mutants required for this work, we first constructed E. coli TK412 (idn $\mathrm{O}<>k a n)$ using recombineering [Yu, et al., 2000 (Fig. 2A)]. First, an 1150 bp kanamycine recombinant cassette with $i d n \mathrm{O}$ internal sequences on its flanks was generated by PCR from E. coli Y1088 proA::Tn5, kan (Young and Davis, 1983) chromosomal DNA, using PCR primers

TABLE I

Strains of E. coli

\begin{tabular}{|c|c|c|c|c|c|}
\hline \multirow{2}{*}{$\begin{array}{c}\begin{array}{c}\text { Strain Source } \\
\text { Phenotypes on Plat }\end{array} \\
\text { M1 }\end{array}$} & \multirow{2}{*}{$\begin{array}{l}\text { Sex } \\
\text { HfrC }\end{array}$} & \multirow[t]{2}{*}{ Relevant Characteristics } & \multicolumn{2}{|c|}{$\begin{array}{l}\text { Phenotypes on plates } \\
(24 \text { h) BTB Mineral }\end{array}$} & \multirow{2}{*}{$\begin{array}{c}\text { Source } \\
{[6]}\end{array}$} \\
\hline & & & $\mathrm{Y}$ & $\mathrm{Gnt}^{+}$ & \\
\hline C177 & HfrG & $\operatorname{gnt} 177, \Delta($ bio $\mathrm{H}-a s d)$ & $\mathrm{Y}$ & $\mathrm{Gnt}^{+}$ & This Lab. \\
\hline Y1088 & $\mathrm{F}^{-}$ & proA::Tn5, Kan ${ }^{\mathrm{R}}$ & Y & $\mathrm{Gnt}^{+}$ & [29] \\
\hline TAF394 & $\mathrm{HfrC}$ & $\lambda$ cI857 $\Delta($ cro-bio $A)$ & Y & $\mathrm{Gnt}^{+}$ & This Lab. \\
\hline DY329 & $\mathrm{F}^{-}$ & $\Delta$ lac U169 nadA::Tn10, gal490 $\lambda$ cI857 $\Delta($ cro-bioA $)$ & Y & $\mathrm{Gnt}^{+}$ & [28] \\
\hline TK411 & $\mathrm{HfrC}$ & $\lambda \mathrm{cI} 857 \Delta($ cro-bioA $), i d n \mathrm{O}<>k a n$ & $\mathrm{Y}$ & $\mathrm{Gnt}^{+}$ & This study \\
\hline TK412 & $\mathrm{HfrC}$ & $i d n \mathrm{O}<>k a n$ & Y & $\mathrm{Gnt}^{+}$ & This study \\
\hline TK416 & HfrG & $\Delta($ bioH-gnt $\mathrm{T}-m a l \mathrm{~A}-g l p \mathrm{D}$, gntKU, gnt $\mathrm{R}$ asd $)$ his, gnt $177, i d n \mathrm{O}<>k a n$ & $\mathrm{~W}$ & Gnt $^{-}$ & This study \\
\hline TGN282 & $\mathrm{F}^{-}$ & gntK, gntV, his, trp, xyl, gal & $\mathrm{W}$ & Gnt $^{-}$ & This Lab. \\
\hline TK424 & HfrG & gnt $\mathrm{K}$, gnt 177 , his, idn $\mathrm{O}<>k a n$ & $\mathrm{~W}$ & Gnt $^{-}$ & This study \\
\hline TK425 & HfrG & gntK, gnt 177 , his & $\mathrm{Y}$ & $\mathrm{Gnt}^{+}$ & This study \\
\hline TUR285 & $\mathrm{F}^{-}$ & malA-glpD-asd, gntV zhg21::Tn10, his, trp, xyl, gal & Y & $\mathrm{Gnt}^{+}$ & This Lab. \\
\hline TK414 & $\mathrm{HfrC}$ & $i d n \mathrm{O}<>k a n, \mathrm{Tet}^{\mathrm{R}}$, malA & Y & $\mathrm{Gnt}^{+}$ & This study \\
\hline TK428 & $\mathrm{HfrC}$ & $i d n \mathrm{O}<>k a n, \mathrm{Tet}^{\mathrm{S}}, \mathrm{Mal}^{+}$, gnt $\mathrm{K}$ & $\mathrm{W}^{\mathrm{a}}$ & $\mathrm{Gnt}^{-\mathrm{b}}$ & This study \\
\hline TK430 & $\mathrm{HfrC}$ & $i d n \mathrm{O}<>k a n, \mathrm{Tet}^{\mathrm{S}}, \mathrm{Mal}^{+}$ & $\mathrm{Y}$ & $\mathrm{Gnt}^{+}$ & This study \\
\hline
\end{tabular}

All the strains are E. coli K12 derivatives. The genetics markers were as previously described (Berlyn et al., 1996). Y (yellow) and W (white) colonies on BTB gluconate plates indicate fermenting and non-fermenting phenotypes respectively. The colonies were tested by streaking fresh colonies and scoring after $24 \mathrm{~h}$ incubation. Gnt ${ }^{+}$

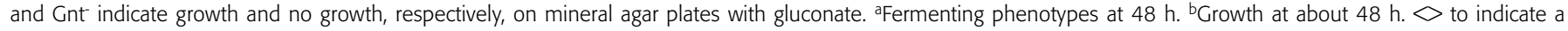
replacement generated by homologous recombination techniques. 
PAHNO1 (5' 'CAGGTGGCCGTTTACGAAATCAGAGGCTTTTGAAGAAAGGAACA CCGCATCAGAaGAaCTCGTCAAGAAG $\left.{ }^{\prime}\right)$ and PAHNO2 (5' ${ }^{\prime}$ GCAGCAAAAGT CCAGCTTGTTTTCTAAGAGATAAATAAAGAAATAATACACATGGACAGCAAGCGAA CCG3'). Second, the recombinant cassette was used to transform E. coli TAF394 $[(\lambda \mathrm{cl} 857 \Delta($ cro-bioA $)]$, a suitable lambda lysogen for promoting linear recombination. Third, E. coli TK411 $\left[\left(\lambda \mathrm{cI} 857 \Delta\right.\right.$ (cro-bioA) idn $\mathrm{O}<>$ kan] a lysogen $\mathrm{Kan}^{\mathrm{R}}$ transformant, was cured from the defective prophage by transducing it to $\mathrm{Bio}^{+}$ at $42{ }^{\circ} \mathrm{C}$ with $\mathrm{P} 1$ phage grown in E. coli M1. Finally, we selected $i d n \mathrm{O}<>$ kan transductant $E$. coli $\mathrm{TK} 412$ (idn $\mathrm{O}<>k a n$ ) for later work.

The $i d n \mathrm{O}$ gene $(850 \mathrm{bp})$ only or kan inserted (1250 bp) were amplified with primers PAH5: 5'CGGAATTCCGGGGGGCTGTTAAACAGC CAC3' and PAH6: 5'CGgGatcccGagataAataAaggaAtaAta3'(Fig. 3).

To obtain isogenic $g n t \mathrm{~K}, i d n \mathrm{O}<>k a n E$. coli strains with or without the gnt177 mutation, phage P1 grown in E. coli TK412 was used to transduce E. coli $\mathrm{C} 177$ to $\mathrm{Kan}^{\mathrm{R}}$ (Fig. 2B). E. coli TK416, a Kan ${ }^{\mathrm{R}}$ transductant and E. coli C177, were in turn made $g n t \mathrm{~T}^{+}, g n t \mathrm{~K}, g n t \mathrm{U}^{+}$by transducing them to $\mathrm{Mal}^{+}, \mathrm{Asd}^{+}$and restoring their bioH-asd regions with phage P1 grown in E. coli TGN282 (gntK). Two transductants were selected, E. coli TK424 (gntK, idn $\mathrm{O}<>$ kan, gnt177) and E. coli $\mathrm{TK} 425$ (gntK, gnt177) and saved for use in this work.

In order to obtain a second and similar pair of E. coli mutants that lacked the gnt177 mutation, strain TK412 was made GntV dependent to growth in gluconate by incorporating it a gntK allele in two steps (Fig. 2A). First, it was transduced to $\mathrm{Tet}^{\mathrm{R}}, \mathrm{Mal}^{-}$with $\mathrm{P} 1$ phage grown in E. coli TUR285. Second, a selected transductant E. coli TK414, was in turn transduced to $\mathrm{Mal}^{+}$with phage P1 grown in E. coli TGN282 (gntK). Among the $\mathrm{Tet}^{\mathrm{S}}$ transductants, two phenotypes arose on BTB gluconate plates: one formed white non-fermenting colonies after $24 \mathrm{~h}$ of incubation that became yellow after $48 \mathrm{~h}$ incubation. The other formed unchanging, yellow fermenting colonies. It is known (Istúriz et al., 1986) and demonstrated below, that such phenotypes indicate the functioning of the thermosensitive $(\mathrm{GntV})$ and thermoresistant (GntK alone or mixed with GntV) gluconate kinases respectively. A transductant of each type, E. coli TK428 and E. coli TK430 respectively, was saved for subsequent studies. PCR analysis confirmed the genotypes of mutants (not shown).

\section{Chemicals}

D-gluconic acid (potassium salt), pyrimidine nucleotides, sugars, amino acids and most other chemicals were purchased from Sigma. Media were from L-Himedia Lab. Primers were from Promega and GiBcoBRL.

\section{RESULTS}

Characteristics of E. coli mutants TK424 (idnO<>kan, gntK, gnt177) and TK425 (gntK, gnt177)

Because E. coli mutant TK425 carries the gnt177 and gntK mutations, its growth in gluconate must depend on the inducible expression of the idnR regulon (idnDOTR and $g n t \mathrm{~V}$

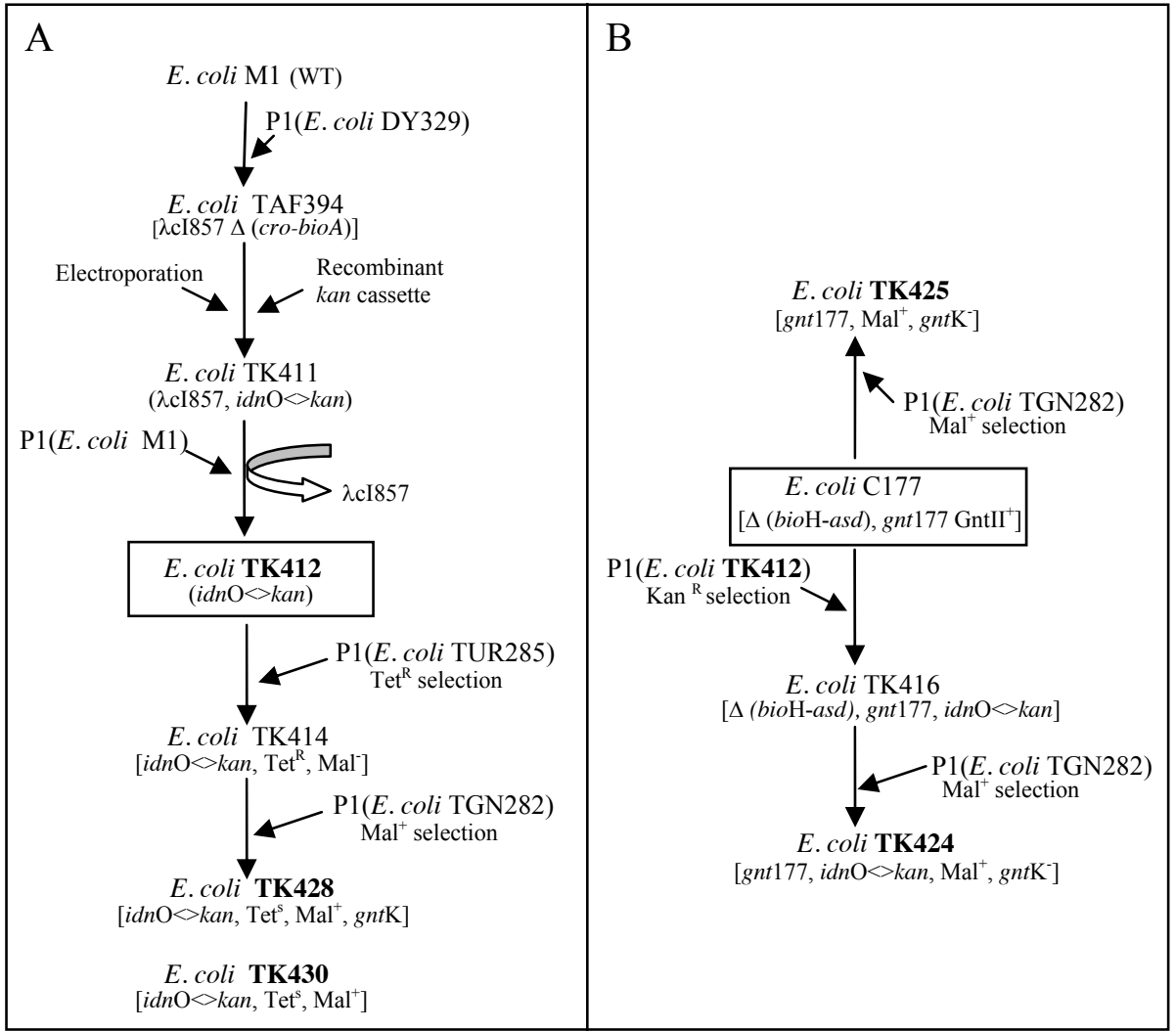

Fig. 2. Construction of $E$. coli mutants: For markers not indicated, see Table I. 
operons) by the 5 KG-IdnR complex (Ramírez, 2004). In this case, the inducer $5 \mathrm{KG}$ is formed from gluconate by the IdnO activity. Consequently, the set formed by this mutant and its isogenic $E$. coli TK424 was suitable to confirm the efficiency of the inserted kan cassette to abort the IdnO activity.

The above mutants grew on LB plates and mineral plates supplemented with maltose or fructose but in contrast to the gntK, gnt177 control strain TK425, E. coli TK424 (idnO $<>k a n$, gnt $\mathrm{K}$, gnt177) was $\mathrm{Kan}^{\mathrm{R}}$ and required $5 \mathrm{KG}$ to grow on mineral plates with gluconate. Moreover, the colonies of E. coli TK424 were white nonfermenting on BTB-gluconate plates, but yellow fermenting after $48 \mathrm{~h}$ incubation if supplemented with 5KG (Table II). In agreement with these results, although both mutants displayed normal generation times in MM with fructose (57 and $59 \mathrm{~min}$ ) and fructose plus gluconate (58 and 65 $\mathrm{min})$, E. coli TK424 required $5 \mathrm{KG}$ to grow in gluconate and this growth had a lag period and a doubling time (300 and $242 \mathrm{~min}$, respectively) that were longer than those of E. coli C177 (240 and $180 \mathrm{~min}$ ) and the isogenic E. coli TK425 (30 and $80 \mathrm{~min}$ ) grown in MM supplemented with gluconate (Table III).

The gluconate kinase activity was also measured in E. coli TK424 and TK425 grown in MM with fructose, fructose plus gluconate, and this substrate, with and without 5KG. E. coli C177 grown in MM with gluconate, was used as an additional control (Table IV). Where this activity was detected, it was thermosensitive and expressed in inducible form. The level displayed by E. coli TK424 grown in gluconate supplemented with 5 KG [44 $\mathrm{nmol} \mathrm{min}^{-1}$ (mg protein) ${ }^{-1}$ ] was lower than those expressed in E. coli C177 and TK425 [62 and $106 \mathrm{nmol} \mathrm{min}^{-}$ $\left.{ }^{1}(\mathrm{mg} \text { protein })^{-1}\right]$ grown in the same medium without $5 \mathrm{KG}$ respectively (Table IV).

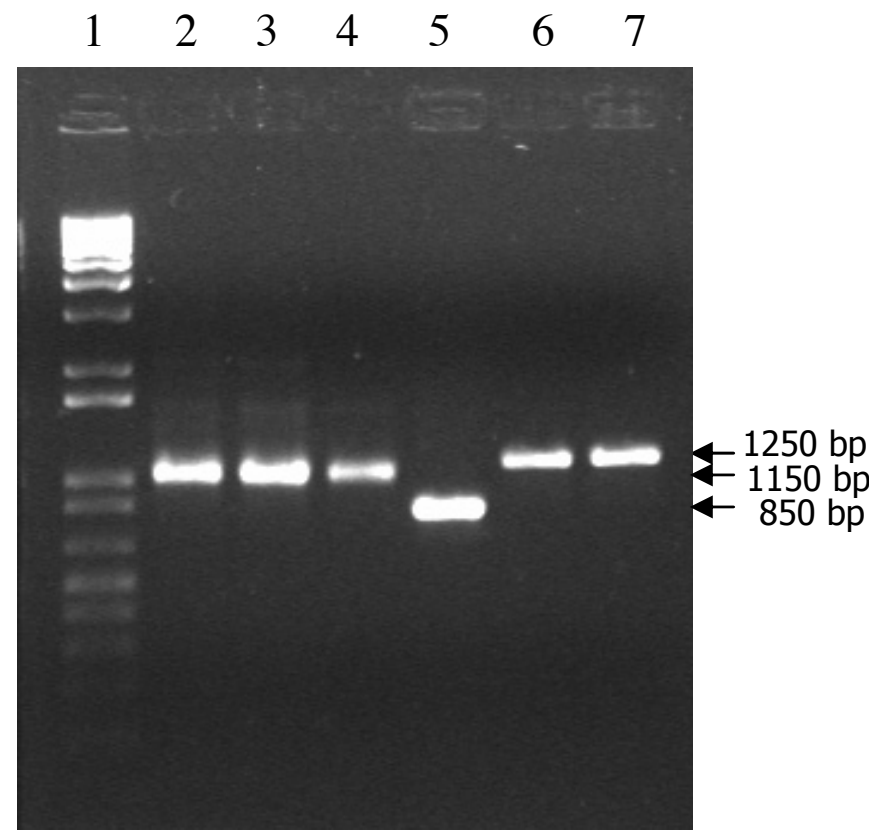

Fig. 3. Electrophoretic analysis in $0.8 \%$ agarose gel of PCR products. Lane 1, $1 \mathrm{~Kb}$ DNA ladder; lanes 2,3 and 4 , kan cassettes from E. coli Y1088, TK411 and TK412; lane 5, idnO from $E$ coli TAF394; lanes 6 and 7, idnO $<$ kan from E. coli TK411 and TK412.
Characteristics of E. coli mutants TK428 (idnO<>kan, gntK, Tet $\left.{ }^{S}\right)$ and TK430 (idnO<>kan)

Since these mutants lack the mutation gnt177, the control on the gnt $\mathrm{V}$ expression should be as in E. coli wild type, therefore, they were suitable to investigate whether this expression in cells grown in gluconate depends on $5 \mathrm{KG}$ as inducer and is coordinated with that of the operon $i d n$ DOTR. This is just what occurs when E. coli is grown in idonate and the inducer $5 \mathrm{KG}$ is formed from idonate by the IdnD activity (Bausch et al., 1998). Both mutants grew on MM plates supplemented with maltose, fructose, LB plus kanamycine but, as expected, did not grow on LB plus tetracycline (Table II). Interestingly, in agreement with their fermenting phenotypes displayed on BTB-gluconate plates (Table II), these mutants grew in MM supplemented with gluconate without requiring 5 KG (Table III); however, the lag period $(245 \mathrm{~min})$ and doubling time $(155 \mathrm{~min})$ showed by $E$. coli TK428 were notably higher than those in E. coli TK430 (50 and $60 \mathrm{~min}$ respectively).

The level of specific thermosensitive ( $70 \%$ heat inactivated) gluconate kinase expressed in E. coli TK428 [40 nmol min- ${ }^{1}$ (mg protein) ${ }^{-1}$ ] did not increase with the addition of $5 \mathrm{KG}$ to the medium and was significantly lower than that displayed by $E$. coli TK430 [141 nmol min ${ }^{-1}$ (mg protein) ${ }^{-1}$ ] expressing mainly the thermoresistant GntK (7\% heat inactivated; Table IV).

\section{DISCUSSION}

The idnR regulon, induced by $5 \mathrm{KG}$ in $E$. coli grown in idonate, includes the gnt $\mathrm{V}$ gene encoding a thermosensitive gluconate kinase which is also induced in gluconate grown cells. As it was not known whether in this case $5 \mathrm{KG}$ is the inducer, the research presented here was addressed to elucidating this question. Our results indicate that $g h t \mathrm{~V}$ is expressed in the absence of $5 \mathrm{KG}$ when gluconate is the substrate. They were obtained through the construction and comparative analysis of two sets of isogenic E. coli gntK, $i d n \mathrm{O}<>$ kan mutants, differing by the presence of the mutation gnt 177 in one of them.

Because idonate is not commercially available, the gluconate phenotype displayed by the set of E. coli idn $\mathrm{O}$ kancassette inserted mutants carrying the gnt 177 mutation, was of central importance in the present work. Since in these mutants the idn regulon (idnDOTR operon plus $g n t \mathrm{~V}$ ) is induced by $5 \mathrm{KG}$ in cells growing in gluconate, they were not only suitable to demonstrate the efficiency of the $i d n \mathrm{O} k a n$-cassete insertion to abort the IdnO activity, but also permitted determining that in similar mutants lacking the gnt 177 mutation, gnt $\mathrm{V}$ expression does not involve $5 \mathrm{KG}$ as the inducer in cells cultivated in gluconate.

In the above context, it was demonstrated that while $5 \mathrm{KG}$ is essential for E. coli TK424 (idn $\mathrm{O}<>k a n, g n t \mathrm{~K}, g n t 177)$ to grow in gluconate, it is not required by the isogenic E. coli TK425 $\left(i d n \mathrm{O}^{+}\right)$control (Table III). Contrary to E. coli TK424, E. coli TK428 (idn $\mathrm{O}<>k a n$, gntK) grows in gluconate without requiring 5 KG despite being blocked in the synthesis of this inducer. This indicates that under this condition $g n t \mathrm{~V}$ is expressed in absence of $i d n$ DOTR operon induction (Table III).The $5 \mathrm{KG}$ requirement of E. coli TK424 for growth on MM with gluconate indicated that the inserted kan cassette eliminated IdnO activity so it could be assumed that it is also absent in both E. coli TK428 and E. coli TK430. 
TABLE II

Phenotypes on plates of strains of $E$. coli

\begin{tabular}{lccccc}
\hline \multicolumn{1}{c}{ Media } & TK424 & TK425 & TK428 & TK430 & C177 \\
\hline LB Tetracycline & - & - & - & - & - \\
Maltose MM & + & + & + & + & - \\
Fructose MM & + & + & + & + & + \\
Gluconate MM & Gnt $^{-}$ & Gnt $^{+}$ & Gnt $^{+b}$ & Gnt $^{+}$ & Gnt $^{+}$ \\
Gluconate MM + 5 KG & Gnt $^{+b}$ & Gnt $^{+}$ & n.d & Gnt $^{+}$ & Gnt $^{+}$ \\
BTB, Gluconate & W & Y & W & Y & Y \\
BTB, Gluconate + 5 KG & W & Y & W & Y & Y \\
LB Kanamycine. & + & - & + & + & - \\
\hline
\end{tabular}

Y (yellow), W (white), $\mathrm{Gnt}^{+}$, Gnt ${ }^{-}$a and ${ }^{\mathrm{b}}$ respectively, indicate as described in Table I. + and - signs indicate growth and no growth on the respective plates. n.d, not determined.

TABLE III

Doubling times (min) of strains of $E$. coli

\begin{tabular}{|c|c|c|c|c|c|c|c|c|c|c|}
\hline \multirow{2}{*}{ Carbon Source } & \multicolumn{2}{|c|}{ TK424 } & \multicolumn{2}{|c|}{ TK425 } & \multicolumn{2}{|c|}{ TK428 } & \multicolumn{2}{|c|}{ TK430 } & \multicolumn{2}{|c|}{ C177 } \\
\hline & LP & DT & LP & DT & LP & DT & LP & DT & LP & DT \\
\hline Fructose & $\sim 20$ & 57 & $\sim 30$ & 59 & $\sim 20$ & 55 & $\sim 25$ & 53 & n.d & n.d \\
\hline Fructose + Gluconate & $\sim 20$ & 58 & $\sim 20$ & 65 & n.d & n.d & n.d & n.d & n.d & n.d \\
\hline Gluconate & no & & $\sim 40$ & 82 & $\sim 245$ & 155 & $\sim 50$ & 60 & $\sim 240$ & 180 \\
\hline Gluconate $+5 \mathrm{KG}(0.4 \%)$ & $\sim 300$ & 242 & $\sim 30$ & 80 & $\sim 240$ & 222 & n.d & n.d & n.d & n.d \\
\hline
\end{tabular}

Cells were grown aerobically on MM with fructose, collected during the exponential phase, centrifuged (3000 rpm., Sorval SS34), resuspended in the same medium up to 300 Klett units (KU, about $10^{9}$ cells $\mathrm{ml}^{-1}$ ) and starved during 30 min at $37^{\circ} \mathrm{C}$. New cultures were initiated at about 10 UK (approximately $10^{7}$ cells $\mathrm{ml}^{-1}$ ) with the indicated carbon sources at 0.2\%. LP, lag phase; DT, doubling time; approximately; n.d, not determined.

TABLE IV

Gluconate kinase activities in E. coli strains

\begin{tabular}{|c|c|c|c|c|c|}
\hline Carbon source & TK424 & TK425 & TK428 & TK430 & C177 \\
\hline Fructose & $<0.01$ & $<0.01$ & $<0.01$ & $<0.01$ & $<0.01$ \\
\hline Fructose + Gluconate & $<0.01$ & $47 \pm 5(70)$ & n.d & n.d & n.d \\
\hline Fructose + Gluconate $+5 \mathrm{KG}$ & $<0.01$ & $61 \pm 7$ & n.d & n.d & n.d \\
\hline Gluconate & no growth & $106 \pm 8(85)$ & $40 \pm 4(70)$ & $141 \pm 7(7)$ & 62 \\
\hline Gluconate $+5 \mathrm{KG}$ & $44 \pm 5(90)$ & n.d & $36 \pm 6(97)$ & n.d & n.d \\
\hline
\end{tabular}

Cells were grown as indicated in Table III. New cultures without previous starvation were grown up to $120 \mathrm{KU}$ in MM with the indicated carbon sources at $0.2 \%$. n.d, not determined; Numbers in parenthesis indicate gluconokinase lability (percentage of activity lost after three hours preincubation at $30{ }^{\circ} \mathrm{C}$ ). The values for the activities represent means \pm standard deviations from two independent experiments. For units, see Materials and methods. 
As demonstrated, E. coli TK428 gntV expression is activated by gluconate in the absence of 5 KG. Since GntR interacts with gluconate to control the gntR regulon, and GntR binding sites are included in the $g n t \mathrm{~V}-i d n \mathrm{D}$ intergenic regulatory region of the idnR regulon, this same complex might be also involved in $g n t \mathrm{~V}$ induction. Interestingly, GntR was found to have a negative effect on the expression of GntII genes in gntRdisrupted strains carrying single copies of gntV-lacZ or idnDlacZ fusions. This effect was not observed by the addition of gluconate, presumably due to the formation of a Gnt-GntR complex (Tsunedomi et al., 2003b).

The lack of idnDOTR expression in E. coli does not alter the gluconate phenotype

E. coli $\mathrm{TK} 430\left(\mathrm{GntK}^{+}\right.$, idn $\left.\mathrm{O}<>\mathrm{kan}\right)$ grows in $\mathrm{MM}$ gluconate with a shorter generation time (60 vs. $155 \mathrm{~min}$; Table III) and has higher levels of gluconokinase [141 vs. $40 \mathrm{nmol} \mathrm{min}^{-1}$ (mg protein) $)^{-1}$; Table IV] than E. coli $\mathrm{TK} 428\left(\mathrm{GntK}^{-}\right.$, idn $\left.\mathrm{O}<>k a n\right)$. Notably, while the gluconate kinase expressed in this mutant is thermosensitive (70\% inactivated), that expressed by E. coli TK430 is mainly thermoresistant GntK (7\% inactivated; Table IV). Despite lacking the ability to form $5 \mathrm{KG}$ from the substrate, this characteristic of E. coli TK430 and its short lag period (25 min; Table III) in MM with gluconate are attributes of a wild type gluconate phenotype.

The idonate-gluconate crosstalk in E. coli wild type

The characteristics of the two sets of E. coli mutants used here would seem to reveal an important and novel physiologic aspect by which the gene $g n t \mathrm{~V}$ is induced by $5 \mathrm{KG}$ or gluconate depending upon whether idonate or gluconate is metabolized. This alternative induction of $g n t \mathrm{~V}$ might be of importance for the development of the bacteria in its natural environment where, as opposed to lab conditions, substrate concentrations are very low. In such a situation, it is not so obvious for energy-saving reasons that the utilization of either substrate requires the induction of both regulons; i.e., idnR and gntR. The alternative induction of the E. coli gnt $\mathrm{V}$ gene reported here would seem to impede this situation by being coordinated with that of the $i d n$ DOTR operon or the $g n t R$ regulon depending on which substrate, idonate or gluconate, is metabolized. It is of interest to advance in the molecular mechanisms associated with this alternative expression of $g n t \mathrm{~V}$.

\section{ACKNOWLEDGEMENTS}

This work was supported by FONACIT, Grant N ${ }^{\circ}$ S12001000704 and CDCH-Universidad Central de Venezuela, Grant No PI 030063082006.

\section{REFERENCES}

BACHI B, KORNBERG HL (1975) Genes involved in the uptake and catabolism of gluconate by Escherichia coli. J Gen Microbiol 90: 321-335.

BAUSCH C, PEEKHAUS N, UTZ C, BLAIS T, MURRAY E, LOWARY T, CONWAY T (1998) Sequence analysis of the GntII (Subsidiary) system for gluconate metabolism reveals a novel pathway for L-idonic acid catabolism in Escherichia coli. J Bacteriol 180: 3704-3710.

BAUSCH C, RAMSEY M, CONWAY T (2004) Transcriptional organization and regulation of the L-idonic acid pathway (GntII System) in Escherichia coli. J Bacteriol 186: 1388-1397.

BURLAND V, PLUNKET III G, SOFIA KJ, DANIELS DL, BLATTNER FR (1995) Analysis of the Escherichia coli genome VI: DNA sequence of the region from 92.8 though 100 minutes. Nucleics Acids Res 23: 2105-2119.

COELLO N, ISTÚRIZ T (1992) The metabolism of gluconate in Escherichia coli. A study in continuous culture. J Basic Microbiol 32: 309-315.

FRAENKEL DG, HORECKER BL (1964) Pathways of D-glucose metabolism in Salmonella typhimurium. J Biol Chem 239: 2765-2771.

ISTÚRIZ T, VITELLI-FLORES J, MARDENI J (1979) El metabolismo del gluconato en Escherichia coli. Estudio de una mutante delecionada en la región bioH-asd del mapa cromosómico. Acta Cient Vlana 30: 391-395.

ISTÚRIZ T, PALMERO E, VITELLI-FLORES J (1986) Mutations affecting gluconate catabolism in Escherichia coli. Genetic mapping of the locus for the thermosensitive gluconokinase. J Gen Microbiol 132: 3209-3219.

IZU H, ADACHI O, YAMADA M (1997) Gene organization and transcriptional regulation of the gntRKU operon involved in gluconate uptake and catabolism of Escherichia coli. J Mol Biol 267: 778-793.

MILLER JH (1992) A short course in Bacterial Genetics. Cold Spring Harbor Laboratory Press. Cold Spring Harbor, New York.

PEEKHAUS N, CONWAY T (1998) Positive and negative transcriptional regulation of the Escherichia coli gluconate regulon gene gnt $\mathrm{T}$ by GntR and the AMP (cAMP)-cAMP receptor protein complex. J Bacteriol 180: 1777-1785.

RAMIREZ A (2004) El metabolismo del ácido glucónico en Escherichia coli. Estudios moleculares del sistema subsidiario GntII. Tesis Doctoral. Facultad de Ciencias, Universidad Central de Venezuela, Caracas, Venezuela.

RAMIREZ A, ROSALES I, PORCO A, DÍAZ JC, ISTÚRIZ T (2007) The metabolism of gluconate in Escherichia coli. Physiological evidence of a regulatory effect of IdnR on the expression of the gntR regulon operons. Acta Cient Vlana 58: 21-28.

SAMBROOK J, FRITSCH E, MANIATIS T (1989) Molecular cloning: a laboratory manual, 2nd ed. Cold Spring Harbor Laboratory Press, Cold Spring Harbor, New York.

TANAKA SS, LERNER A, LIN EC (1967) Replacement of a phosphoenolpyruvate-dependent phosphotransferase by a nicotinamide adenine dinucleotide-linked dehydrogenase for the utilization of mannitol. J Bacteriol 93: 642-648.

TONG S, PORCO A, ISTURIZ T, CONWAY T (1996) Cloning and molecular genetic chacarterization of the Escherichia coli gnt $\mathrm{R}$, gnt $\mathrm{K}$ and gnt $\mathrm{U}$ genes of GntI, the main system for gluconate metabolism. J Bacteriol 178: 32603269.

TSUNEDOMI R, IZU H, KAWAI T, MATSUSHITA K, FERENCI T, YAMADA M (2003 a) The activator of GntII genes for gluconate metabolism, GntH, exerts negative control of GntR-regulated GntI genes in Escherichia coli. J Bacteriol 185: 1783-1795.

TSUNEDOMI R, IZU H, KAWAI T, YAMADA M (2003 b) Dual control by regulators, GntH and GntR, of the GntII genes for gluconate metabolism in Escherichia coli. J Mol Microbiol 6: 41-56

YOUNG RA, DAVIS RW (1983) Yeast RNA polymerase II genes: Isolation with antibody probes. Science 222: 778-782.

YU D, ELLIS HL, LEE E, JEMKINS UA, COPELAND NG, COURT DL (2000) An efficient recombination system for chromosome engineering in Escherichia coli. PNAS 97: 5978-5983.

ZWAIG N, NAGEL DE ZWAIG R, ISTÚRIZ T, WECKSLER M (1973) Regulatory mutations affecting the gluconate system in Escherichia coli. J Bacteriol 114: 469-473 
